\title{
Vitamin D as Modulator of Drug Concentrations: A Study on Two Italian Cohorts of People Living with HIV Administered with Efavirenz
}

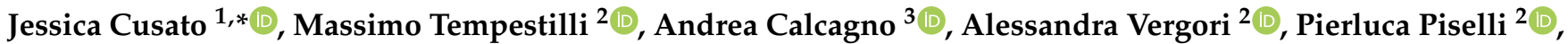 \\ Miriam Antonucci ${ }^{1}$, Valeria Avataneo ${ }^{1}{ }^{(\mathbb{0}}$, Alice Palermiti ${ }^{1}{ }^{10}$, Stefania Notari ${ }^{2}$, Andrea Antinori ${ }^{2}$, \\ Giovanni Di Perri ${ }^{3}$, Chiara Agrati ${ }^{2}{ }^{10}$ and Antonio D'Avolio ${ }^{1}$
}

1 Laboratory of Clinical Pharmacology and Pharmacogenetics, Department of Medical Sciences, Amedeo di Savoia Hospital, University of Turin, 10149 Turin, Italy; miriam.antonucci20@gmail.com (M.A.);

valeria.avataneo@unito.it (V.A.); alice.palermiti@unito.it (A.P.); antonio.davolio@unito.it (A.D.)

2 National Institute for Infectious Diseases Lazzaro Spallanzani IRCCS, 00149 Rome, Italy; massimo.tempestilli@inmi.it (M.T.); alessandra.vergori@inmi.it (A.V.); pierluca.piselli@inmi.it (P.P.); stefania.notari@inmi.it (S.N.); andrea.antinori@inmi.it (A.A.); chiara.agrati@inmi.it (C.A.)

3 Unit of Infectious Diseases, Department of Medical Sciences, Amedeo di Savoia Hospital, University of Turin, 10149 Turin, Italy; andrea.calcagno@unito.it (A.C.); giovanni.diperri@unito.it (G.D.P.)

* Correspondence: jessica.cusato@unito.it; Tel.: +39-011-4393867; Fax: +39-011-4393996

Citation: Cusato, J.; Tempestilli, M.; Calcagno, A.; Vergori, A.; Piselli, P.; Antonucci, M.; Avataneo, V.;

Palermiti, A.; Notari, S.; Antinori, A.; et al. Vitamin D as Modulator of Drug Concentrations: A Study on Two Italian Cohorts of People Living with HIV Administered with Efavirenz. Nutrients 2021, 13, 3571. https://doi.org/10.3390/nu13103571

Academic Editors: Carsten Carlberg and Premysl Mladenka

Received: 6 September 2021

Accepted: 9 October 2021

Published: 12 October 2021

Publisher's Note: MDPI stays neutral with regard to jurisdictional claims in published maps and institutional affiliations.

Copyright: (c) 2021 by the authors Licensee MDPI, Basel, Switzerland. This article is an open access article distributed under the terms and conditions of the Creative Commons Attribution (CC BY) license (https:// creativecommons.org/licenses/by/ $4.0 /)$

\begin{abstract}
To date, vitamin D seems to have a significant role in affecting the prevention and immunomodulation in COVID-19 disease. Nevertheless, it is important to highlight that this prohormone has other several activities, such as affecting drug concentrations, since it regulates the expression of cytochrome P450 (CYP) genes. Efavirenz (EFV) pharmacokinetics is influenced by CYPs, but no data are available in the literature concerning the association among vitamin D levels, seasonality (which affects vitamin D concentrations) and EFV plasma levels. For this reason, the aim of this study was to evaluate the effect of 25-hydroxy vitamin D (25(OH)D3) levels on EFV plasma concentrations in different seasons. We quantified $25(\mathrm{OH}) \mathrm{D} 3$ by using chemiluminescence immunoassay, whereas EFV plasma concentrations were quantified with the HPLC-PDA method. A total of 316 patients were enrolled in Turin and Rome. Overall, 25(OH)D3levels resulted in being inversely correlated with EFV concentrations. Some patients with EFV levels higher than $4000 \mathrm{ng} / \mathrm{mL}$ showed a deficient 25(OH)D3 concentration in Turin and Rome cohorts and together. EFV concentrations were different in patients without vitamin D supplementation, whereas, for vitamin D-administered individuals, no difference in EFV exposure was present. Concerning seasonality, EFV concentrations were associated with $25(\mathrm{OH}) \mathrm{D} 3$ deficiency only in winter and in spring, whereas a significant influence was highlighted for 25(OH)D3 stratification for deficient, insufficient and sufficient values in winter, spring and summer. A strong and inverse association between 25(OH)D3and EFV plasma concentrations was suggested. These data suggest that vitamin D is able to affect drug exposure in different seasons; thus, the achievement of the clinical outcome could be improved by also considering this pro-hormone.
\end{abstract}

Keywords: plasma concentrations; vitamin D; seasonality; drug metabolism

\section{Introduction}

Vitamin D is recognized as a prohormone. Vitamin D is classified as a nutrient, and it is also synthesized by the human body through the action of sunlight. These dual sources of vitamin D make it challenging to develop dietary reference intake values [1].

Worldwide, vitamin D deficiency represents a public health problem in all age groups; however, studies are still lacking in most countries, particularly on risk groups. Data recorded by the National Health and Nutrition Examination Survey (NHANES) show that $79 \%$ of the elderly adult population has vitamin D deficiency or insufficiency [2,3]. This 
phenomenon seems to be frequent in Italy among elderly adults and, particularly, during winter months [4,5]. Different pathologies have been associated with vitamin D deficiency, including COVID-19 [6].

Ultraviolet light is responsible for vitamin D synthesis in skin; cholecalciferol is hydroxylated to calcifediol (25-hydroxy vitamin D, 25(OH)D3) in the liver through cytochrome P-450 (CYP) 27A1 and CYP2R1 and, in the kidney, calcitriol (1,25-dihydroxy vitamin $\mathrm{D}, 1,25(\mathrm{OH}) \mathrm{D} 3)$ is synthesized through CYP27B1. Then 1,25-VD is transported in the bloodstream through the vitamin-D-binding protein (VDBP).

In HIV-positive patients, reduced vitamin D concentrations were often found at various levels of severity and have been linked to low bone-mineral density and related disorders, subclinical vascular disease, kidney function decline, endocrine disorders, liver fibrosis, preterm delivery and neurocognitive impairment [7-12].

Vitamin D modulates the expression of many genes through its receptor (vitamin D receptor, VDR); particularly, it has an impact on the expression of gene-encoding transporters and enzymes responsible for drug transport and metabolism, such as CYPs [13].

Drocourt et al. showed that vitamin D induces CYP3A4 and, to a lesser extent, CYP2B6 and $C Y P 2 C 9$ genes expression in human hepatocytes [14].

Several drugs are metabolized by CYP3A4; its gene shows vitamin D responsive elements (VDRE), and its expression is upregulated in the presence of 1,25(OH)D3. Consequently, vitamin D may alter CYP3A4-metabolized drugs' concentrations, as shown for immunosuppressants: Lindh et al. suggested tacrolimus and sirolimus seasonal variability according to changes in vitamin D levels (which depends on sunlight exposure); they observed lower drug concentration in July to September than in January to March [15]. In addition, vitamin D is able to affect CYP2B6 gene expression; consequently, this enzyme metabolized drugs, for example, Efavirenz (EFV).

Vitamin D may interact with several drugs, potentially altering drug toxicity or efficacy, but also drugs may affect vitamin D metabolism and status [16]. In fact, the 25-hydroxylase CYP3A4, which is a phase 1 biotransformation enzyme for several drugs, as suggested before, is able to convert precursors to $25(\mathrm{OH}) \mathrm{D} 3$.

Moreover, antiretroviral drugs are pregnane $\mathrm{X}$ receptor (PXR) ligands; thus, they are able to activate it and the related pathway [16]. PXR is important when considering xenobiotics and drugs detoxifications; it is able to bind to VDRE, affecting the expression of genes normally regulated by vitamin D. In fact, 24-hydroxylases and other CYPs resulted in being upregulated in the presence of PXR.

Studies reported that in vitro HIV protease inhibitors, particularly ritonavir, inhibit the conversion of 25(OH)D3 to 1,25(OH)D3 and 1,25(OH)D3 degradation [17].

EFV pharmacokinetic exposure shows high inter-patient variability, and it is related to toxicity in terms of neurological problems: Burger et al. analyzed 255 individuals, suggesting $48(18.9 \%)$ patients had EFV toxic concentrations [18]. Furthermore, they highlighted gender and race as important factors determining inter-patient EFV plasmalevel variability. In conclusion, they recommended physicians to pay particular attention to females and non-caucasian ethnicity patients, since they are more predisposed to EFVinduced toxicity. Consequently, it could be useful to evaluate which factors are able to affect EFV exposure, particularly considering that vitamin D seems to influence the expression of CYPs involved in this drug metabolism.

Not many data are available in the literature concerning the association between EFV and 25(OH)D3 levels in Italian patients. Moreover, in clinical practice, vitamin D's use as supplements to prevent and treat a wide range of clinical conditions has increased substantially over the last decade in people living with HIV (PLWH), even in different geographical latitudes.

For these reasons, the aim of this study was to analyze EFV and vitamin D relationship in two cohorts, from Turin (North of Italy) and from Rome (Center of Italy), consisting of HIV-positive patients seen for care, in order to evaluate vitamin D's effect on EFV exposure 
in different seasons. An association between 25(OH)D3 and EFV plasma concentrations was suggested.

\section{Materials and Methods}

\subsection{Study Design}

A retrospective cohort study was performed in PLWH treated at Amedeo di Savoia (Turin, Italy) and National Institute for Infectious Diseases "L. Spallanzani", IRCCS (Rome, Italy) between January 2015 and January 2018.

Inclusion criteria were age $\geq 18$ years, good general condition (without other diseases), on EFV-containing therapy for $>7$ days, absence of any interacting drugs (such as rifampicin, methadone or erythromycin), no co-infection, drug intake $12( \pm 3) \mathrm{h}$ before blood withdrawal and reported medication adherence above $90 \%$ (Ethic Committee approvals: COVID study 53/2018 for Rome and CS2/325 del 8/8/2017 for Turin).

For each patient, the following data were recorded: demographics (e.g., sex and age); HIV stage (according to the Centers for Disease Control and Prevention (CDC)) estimation of adherence according to the proportion of visits "on time" (proportion of visits respecting the deadline given by appointment compared with the total visits); start of first-line therapy; symptoms; diseases and/or concomitant medications at the time of the visit; antiretroviral therapy in progress; time and date of the last administration of antiretroviral drugs.

\subsection{Efavirenz Plasma Concentrations}

Sampling was performed the day after the evening dose of EFV (12 $\pm 3 \mathrm{~h})$. Plasma samples were obtained from a lithium-heparin tube $(7 \mathrm{~mL})$ and were stored in cryovials at $-20{ }^{\circ} \mathrm{C}$ before analysis.

EFV concentrations at $12 \mathrm{~h}$ after intake (C12) were determined by a high-performance liquid chromatography (HPLC) system coupled with a photodiode array (PDA), using solid-phase extraction for frozen plasma samples, according to a previously described and fully validated method [19]. Patients with undetectable concentrations were considered non-adherent and were excluded from the analyses. All patients with EFV exposure higher than the lower limit of quantification were considered eligible for the analysis. EFV C12 therapeutic range is within $1000-4000 \mathrm{ng} / \mathrm{mL}$ [20].

\subsection{Quantification of 25-Hydroxyvitamin D}

Contextually to EFV quantification, total serum 25(OH)D3 was quantified by using a chemiluminescence immunoassay (CLIA; DiaSorin LIAISON ${ }^{\circledR} 25$ OH Vitamin D TOTAL Assay. This method does not allow for us to differentiate between D2 and D3 forms.

Serum Vitamin D levels were classified, according to manufacture reference values, on (i) deficiency ( $\leq 10 \mathrm{ng} / \mathrm{mL}$ ), (ii) insufficiency (11 to $30 \mathrm{ng} / \mathrm{mL}$ ) and (iii) sufficiency $(>30 \mathrm{ng} / \mathrm{mL})[21]$.

\subsection{Statistical Analysis}

All of the continuous variables were tested for normality with the Shapiro-Wilk test. The Kolmogorov-Smirnov test was performed in order to evaluate the distribution, comparing a sample with a reference probability distribution. Non-normally distributed variables were described as median and interquartile range. The correlation between continuous variables was performed by parametric and non-parametric tests (Pearson and Spearman). Non-normal variables were resumed as median values and interquartile range (IQR), whereas categorical variables were resumed as numbers with percentages. Kruskal-Wallis and Mann-Whitney analyses were considered for differences in continuous variables between different groups (such as vitamin D levels stratification and seasons), considering a statistical significance with a two-sided $p$-value $<0.05$. Chi-squared test was used to evaluate differences between categorical variables (such as vitamin D stratification values and EFV-associated cutoff values). 
All of the tests were performed with IBM SPSS Statistics for Windows v.26.0 (IBM Corp., Chicago, IL, USA).

\section{Results}

\subsection{Patients Characteristics}

Characteristics of the 316 analyzed patients are reported in Table 1: 227 patients were enrolled in Turin, whereas 89 individuals were enrolled in Rome.

Table 1. Patients' characteristics. "/" indicates no available data.

\begin{tabular}{|c|c|c|c|c|}
\hline Characteristics & Turin Cohort & Rome Cohort & Total & $p$-Value \\
\hline $\mathrm{n}^{\circ}$ patients & 227 & 89 & 316 & \\
\hline Age (year), median (IQR) & $46(39-51)$ & $45(37.5-53)$ & $44(37.5-49)$ & 0.867 \\
\hline Caucasian ethnicity, n (\%) & $184(81.1)$ & $72(80.9)$ & $256(81)$ & 0.003 \\
\hline Male sex, n (\%) & $177(78)$ & $85(95.5)$ & $262(82.9)$ & $<0.001$ \\
\hline Viral load (copies/mL), median (IQR) & $75.5(28.8-34.8)$ & / & $75.5(28.8-34.8)$ & / \\
\hline CD4 (cells/mL), median (IQR) & $717(553.3-870.0)$ & $546(408.5-685.5)$ & $584(450-746)$ & $<0.001$ \\
\hline Vitamin D levels (ng/mL), median (IQR) & $22.3(15.1-31.2)$ & $21.9(16.1-28.8)$ & $22.3(15.5-30.3)$ & 0.657 \\
\hline Deficiency $(\leq 10 \mathrm{ng} / \mathrm{mL}), \mathrm{n}(\%)$ & $23(10.1)$ & $11(12.4)$ & $34(10.8)$ & 0.565 \\
\hline Insufficiency (11-30 ng/mL), n (\%) & $143(63)$ & $61(68.5)$ & $204(64.6)$ & 0.333 \\
\hline Sufficiency (>30 ng/mL), n (\%) & $61(26.9)$ & $17(19.1)$ & $78(24.7)$ & 0.339 \\
\hline Vitamin D supplementation, n (\%) & $17(7.85)$ & / & $17(7.5)$ & / \\
\hline
\end{tabular}

\subsection{Vitamin D Distribution}

The $25(\mathrm{OH}) \mathrm{D} 3$ levels distribution $(\leq 10,11-30$ and $>30 \mathrm{ng} / \mathrm{mL})$ was reported in Table 1; viral loads for the Rome center were not available, since these data were difficult to obtain after years. Overall, the 25(OH)D3 concentrations were not significantly different in the two cohorts $(p=0.657)$, and in both cohorts, a similar frequency of patients presenting $25(\mathrm{OH}) \mathrm{D} 3$ level below $30 \mathrm{ng} / \mathrm{mL}$ (deficiency $12.4 \%$ vs. $10.1 \%$; insufficiency $68.5 \%$ vs. $63.0 \%$ ) was observed. Furthermore, an increased number of patients had 25(OH)D3 concentrations higher than $30 \mathrm{ng} / \mathrm{mL}$ ( $26.9 \%$ vs. $19.1 \%)$ in the Turin cohort, but without being statistically significance.

\subsection{Efavirenz Distribution According to Vitamin D Levels}

Of note, 25(OH)D3 levels resulted in being inversely correlated with EFV concentrations $\left(\mathrm{r}^{2}=0.016 ; p=0.020\right.$, Supplementary Material Figure S1).

When comparing HIV patients with different 25(OH)D3 levels, we found that significant differences in EFV concentration (deficiency vs. insufficiency, $p=0.001$; deficiency vs. sufficiency, $p<0.001$; insufficiency vs. sufficiency, $p=0.008$; Figure 1) were suggested. In particular, higher drug concentrations in patients with 25(OH)D3 deficiency were highlighted.

A possible association between 25(OH)D3 levels and EFV-associated toxicity by defining a $4000 \mathrm{ng} / \mathrm{mL}$ cutoff for EFV concentration was considered [20]: a significant higher proportion of patients with EFV levels higher than $4000 \mathrm{ng} / \mathrm{mL}$ showed a deficiency in $25(\mathrm{OH}) \mathrm{D} 3$ concentration in Turin $(p=0.017)$ and Rome $(p<0.001)$ cohorts and together $(p<0.001)$ (see Table 2). 


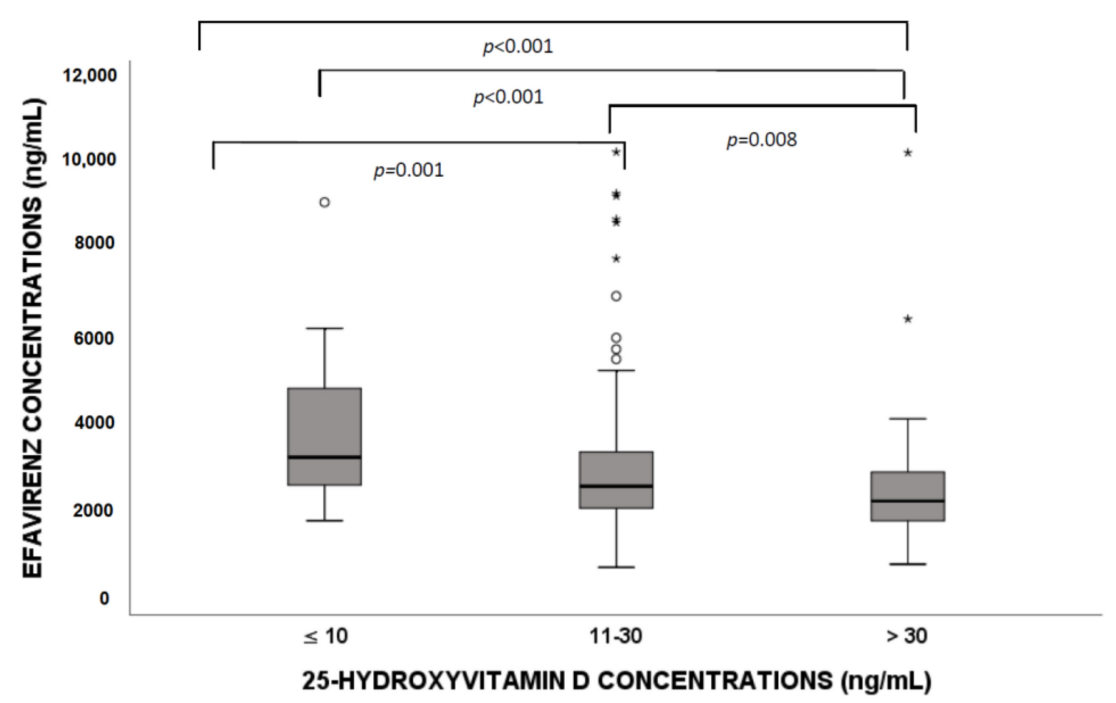

Figure 1. Efavirenz exposure according to 25-hydroxyvitamin D (25(OH)D3) level stratification (deficiency, insufficiency and sufficiency). Circles and stars indicate "out" values (small circle) and "far out" values (star).

Table 2. Efavirenz exposure stratification (< or $\geq 4000 \mathrm{ng} / \mathrm{mL}$ ) in deficient, insufficient and sufficient values of vitamin $\mathrm{D}$ in the two different cohorts and both together. The $p$-values are obtained through chi squared test (crosstabs).

\begin{tabular}{|c|c|c|c|c|c|}
\hline & & $\begin{array}{c}\text { Efavirenz }<4000 \mathrm{ng} / \mathrm{mL} \\
\mathrm{n}(\%)\end{array}$ & $\begin{array}{c}\text { Efavirenz } \geq 4000 \mathrm{ng} / \mathrm{mL} \\
\mathrm{n}(\%)\end{array}$ & $\begin{array}{l}\text { Total } \\
\text { n (\%) }\end{array}$ & \\
\hline \multirow{4}{*}{ Turin } & Deficiency $(\leq 10)$ & $16(69.6)$ & $7(30.4)$ & $23(100)$ & \multirow{4}{*}{$p=0.017$} \\
\hline & Insufficiency $(11-30)$ & $123(86.0)$ & $20(14.0)$ & $143(100)$ & \\
\hline & Sufficiency $(>30)$ & $57(93.4)$ & $4(6.6)$ & $61(100)$ & \\
\hline & Total & $196(86.3)$ & $31(13.7)$ & $227(100)$ & \\
\hline \multirow{4}{*}{ Rome } & Deficiency $(\leq 10)$ & $3(27.3)$ & $8(72.7)$ & $11(100)$ & \multirow{4}{*}{$p<0.001$} \\
\hline & Insufficiency (11-30) & $56(91.8)$ & $5(8.2)$ & $61(100)$ & \\
\hline & Sufficiency $(>30)$ & $17(100)$ & & $17(100)$ & \\
\hline & Total & $76(85.4)$ & $13(14.6)$ & $89(100)$ & \\
\hline \multirow{4}{*}{ Total } & Deficiency $(\leq 10)$ & $19(55.9)$ & $15(44.1)$ & $34(100)$ & \multirow{4}{*}{$p<0.001$} \\
\hline & Insufficiency $(11-30)$ & $179(87.7)$ & $25(12.3)$ & $204(100)$ & \\
\hline & Sufficiency $(>30)$ & $74(94.9)$ & $4(5.1)$ & $78(100)$ & \\
\hline & Total & $272(86.1)$ & $44(13.9)$ & $316(100)$ & \\
\hline
\end{tabular}

Patients were supplemented with vitamin D only in the Turin cohort. In Table 3, patients were divided in supplemented or not, and then, for both groups, 25(OH)D3 stratification for deficient, insufficient and sufficient values was considered. EFV concentrations were statistically different $(p=0.042)$ in patients without vitamin D supplementation, whereas, for vitamin D-administered individuals, no deficient patients were present; in addition, they did not show a statistical significant difference $(p=0.622)$.

\subsection{Seasonality}

Concerning seasonality, EFV concentrations were associated with vitamin D deficiency $(\leq 10 \mathrm{ng} / \mathrm{mL})$ only in winter $(p=0.001$, deficient patients $=11 / 88)$ and in spring $(p=0.017$, deficient patients $=12 / 82)$, but not in summer $(p=0.149$, deficient patients $=1 / 66)$ and autumn $(p=0.494$, deficient patients $=10 / 80)$.

A statistical significance was highlighted for $25(\mathrm{OH}) \mathrm{D} 3$ stratification in winter $(p=0.002)$, spring $(p=0.039)$ and summer $(p=0.011)$, but not for autumn $(p=0.391)$. 
Table 3. Efavirenz levels according to vitamin D supplementation in the Turin cohort. The $p$-values are obtained through chi squared test (crosstabs).

\begin{tabular}{|c|c|c|c|c|c|c|}
\hline & & $\begin{array}{l}\text { Efv Levels < } \\
1000 \mathrm{ng} / \mathrm{mL}\end{array}$ & $\begin{array}{c}\text { Efv Levels } \\
1000-4000 \\
\text { ng/mL }\end{array}$ & $\begin{array}{l}\text { Efv Levels > } \\
4000 \mathrm{ng} / \mathrm{mL}\end{array}$ & Total & \\
\hline \multirow{4}{*}{$\begin{array}{c}\text { No vitamin D } \\
\text { supplementation }\end{array}$} & Deficient $(\leq 10)$ & & $16(69.6)$ & $7(30.4)$ & $23(100)$ & \multirow{4}{*}{$p=0.042$} \\
\hline & Insufficient (11-30) & $5(3.8)$ & $110(83.3)$ & $17(12.9)$ & $132(100)$ & \\
\hline & Normal $(>30)$ & $3(5.5)$ & $49(89.1)$ & $3(5.5)$ & $55(100)$ & \\
\hline & Total & $8(3.8)$ & $175(83.3)$ & $27(12.9)$ & $210(100)$ & \\
\hline \multirow{3}{*}{$\begin{array}{c}\text { Vitamin D } \\
\text { supplementation }\end{array}$} & Insufficient (11-30) & & $8(72.7)$ & $3(27.3)$ & $11(100)$ & \multirow{3}{*}{$p=0.622$} \\
\hline & Normal $(>30)$ & & $5(83.3)$ & $1(16.7)$ & $6(100)$ & \\
\hline & Total & & $13(76.5)$ & $4(23.5)$ & 17 (100) & \\
\hline \multirow{4}{*}{ All } & Deficient $(\leq 10)$ & & $16(69.6)$ & $7(30.4)$ & $23(100)$ & \multirow{4}{*}{$p=0.064$} \\
\hline & Insufficient (11-30) & $5(3.5)$ & $118(82.5)$ & $20(14.0)$ & $143(100)$ & \\
\hline & Normal $(>30)$ & $3(4.9)$ & $54(88.5)$ & $4(6.6)$ & $61(100)$ & \\
\hline & Total & $8(3.5)$ & $188(82.8)$ & $31(13.7)$ & $227(100)$ & \\
\hline
\end{tabular}

\section{Discussion}

Several studies have shown that vitamin D is able to affect drug concentrations [22-25] and clinic features [26-29]. In this context, recently, our group's work (accepted for publication) focused on the seasonality of other antiretroviral drugs, showing a trend in concentrations during the year, especially for etravirine, maraviroc and lopinavir [30].

In this study, 316 PLWH treated with EFV were included. EFV and 25(OH)D3 concentrations were investigated: most of patients had 25(OH)D3 deficiency or insufficiency, as shown in Table 1. This seems to agree with percentages evidenced by Cervero et al., who analyzed a cohort of $352 \mathrm{HIV}$-infected individuals: deficiency was present in $44 \%$, whereas insufficiency was present in $71.6 \%$ [31]. These data are related to patients living in Spain, which has a similar latitude to Italy.

Furthermore, in this study, an inverse correlation between 25(OH)D3 levels and EFV exposure was demonstrated according to what shown by Lindh et al.; in fact, tacrolimus and sirolimus immunosuppressant agents' concentrations decreased with an increased vitamin D level. This could be due to vitamin D's inductive effect on genes encoding for protein involved in these drugs' metabolism and excretion (CYP3A5, CYP2B6 and ABCB1 genes encoding for CYP3A5, CYP2B6 enzymes and for P-glycoprotein transporter) [13,15]. In addition, as shown for tacrolimus and sirolimus, as well as for EFV, seasonality could have an impact in terms of EFV plasma variation.

A possible interaction between 25(OH)D3 and antiretrovirals has been evidenced for other anti-HIV drugs; for example, tenofovir disoproxil fumarate (TDF) is an antiHIV drug which causes bone, endocrine and renal changes, but mechanisms are not well described [32]. In a cohort of 118 patients taking TDF, the authors suggested that the highest quintile of TDF plasma concentrations was associated with increased VDBP, 25(OH)D3 and calcium, but lower 1,25(OH)D3. Furthermore, higher plasma TDF exposure was related to increased VDBP and lower 1,25(OH)D3, suggesting a functional vitamin D deficiency explaining TDF-associated higher parathyroid hormone levels [33].

In the Turin cohort, most of patients showed 25(OH)D3 concentrations higher than $30 \mathrm{ng} / \mathrm{mL}$ and, generally, increased 25(OH)D3 levels: this could be in contrast with the considered latitude, since Rome is much closer to the equator (latitude about $41^{\circ}$ ) compared to Turin (latitude about $45^{\circ}$ ).

However, due to personal sun-exposure behaviors, professional and outdoor activities, the personal ultraviolet (UV) exposure may be low to negligible if an individual does not engage in outdoor activities. Similarly, an individual may live at a higher latitude, with lower ambient UV levels and with a greater outdoor activity, resulting in a higher personal UV exposure [34]. 
Moreover, these high levels in the Turin cohort could be explained by the fact that patients are supplemented only in Turin and not in Rome.

Furthermore, considering the EFV cutoff value associated with side effects, a small number of patients had 25(OH)D3 deficiency in EFV concentrations $<4000 \mathrm{ng} / \mathrm{mL}$ patients compared to the higher percentage in $\geq 4000 \mathrm{ng} / \mathrm{mL}$ ones, confirming vitamin $\mathrm{D}^{\prime} \mathrm{s}$ protective role in terms of toxicity, as shown for other kind of pathologies $[35,36]$.

The relationship between vitamin D and EFV exposure could be explained by EFV metabolism by CYP2B6 and vitamin D (particularly 1,25(OH)D3, the active metabolite) that induces the expression of several genes, such as CYP3A4 and, to a lesser extent, CYP2B6 and $C Y P 2 C 9$ ones, in normal differentiated primary human hepatocytes.

This is the first study reporting vitamin D influence on EFV concentrations in two Italian cohorts of HIV-affected patients; particularly, 25(OH)D3 deficiency $(\leq 10 \mathrm{ng} / \mathrm{mL})$ was associated with higher EFV exposure, with a potential risk of adverse effects. Considering EFV neurotoxicity, even at subclinical levels, this may be relevant: it should be highlighted that, in countries with limited resource, EFV is still widely used.

Hypovitaminosis D is present in several clinical conditions, such as diabetes, cancer or HIV infection, in which prevalence varies from $14 \%$ to $52 \%$ depending on gender, lifestyle, season, ethnicity, geographic position and type of antiretrovirals [37,38]. Furthermore, a recent analysis showed that vitamin D -deficient HIV-infected patients have an increased risk of having neurocognitive impairment, particularly HIV-associated neurocognitive deficit (HAND), which is associated with EFV therapy, also in asymptomatic patients [39-41]. Consequently, for these reasons, it could be very important to conduct vitamin $\mathrm{D}$ and drug concentration evaluation during therapy in order to avoid vitamin $\mathrm{D}$ and EFV (and other drugs) levels predisposing therapy-associated side effects, such as neurocognitive disorders.

This is the first study in this field, but it has some limitations, such as a lack of data on 1,25(OH)D3 and seasonality, but also on EFV toxicity. It would also be useful to take into consideration other drugs metabolized or transported by enzymes and transporters for which genes' expressions are affected by vitamin D.

\section{Conclusions}

In conclusion, this manuscript suggests the association between vitamin $\mathrm{D}$ levels and EFV exposure in two different cohorts of Italian (Rome and Turin) HIV-affected patients, considering their different latitudes. This study highlights the possible role of vitamin $\mathrm{D}$ in predicting EFV levels, despite its reduced use, but it could be useful in order to clarify the involvement of this pro-hormone in affecting other drug concentrations.

Finally, other studies are mandatory in order to better define the role of vitamin D metabolic effects on drugs and their toxicity and to evaluate the possible clinical impact of these findings.

Supplementary Materials: The following are available online at https:/ /www.mdpi.com/article/10 .3390/nu13103571/s1, Figure S1: Scatter plot of Efavirenz exposure and vitamin D levels with its fit line.

Author Contributions: J.C., conceptualization and writing—original draft preparation; M.T., conceptualization and writing—original draft preparation, A.C.; data curation, A.V.; data curation; P.P., software; M.A., formal analyses; V.A., formal analyses; A.P., formal analyses; S.N., writing-review and editing; A.A., visualization; G.D.P., writing — review and editing; C.A., writing-review and editing; A.D., funding acquisition and supervision. All authors have read and agreed to the published version of the manuscript.

Funding: This research received no external funding.

Institutional Review Board Statement: The study was conducted according to the guidelines of the Declaration of Helsinki and approved by the Institutional Ethics Committees: COVID study 53/2018 for Rome and CS2/325 del 8/8/2017 for Turin. 
Informed Consent Statement: Informed consent was obtained from all subjects involved in the study.

Data Availability Statement: Data are available within the text. Patients' data are available upon request, due to privacy and ethical restrictions.

Acknowledgments: We thank CoQua Lab (www.coqualab.it, accessed on 8 October 2021) for its methodological support and assistance in the preparation and execution of the study and analysis.

Conflicts of Interest: A.C. and G.D.P. reports grants from VIIV and GILEAD, as well as personal fees from VIIV, GILEAD, JANSSEN-CILAG, INSMED and MSD, outside the submitted work. A.V. received institutional grant from Gilead Sciences, personal fees and travel grant from Janssen, personal fee from MSD. A.A. has served as a paid consultant to Gilead Sciences, Janssen-Cilag, Merck and ViiV Healthcare and received research institutional grants from Gilead Sciences, Janssen-Cilag and ViiV Healthcare. The other authors declare no potential conflict of interest.

\section{References}

1. Atkinson, S.A. The new dietary reference intakes from the Institute of Medicine for calcium and vitamin D. Perspect. Infirm. 2011, 8,5 .

2. Reiber, H. External quality assessment in clinical neurochemistry: Survey of analysis for cerebrospinal fluid (CSF) proteins based on CSF/serum quotients. Clin. Chem. 1995, 41, 256-263. [CrossRef]

3. National Center for Health Statistics, Centers for Disease Control and Prevention. National Health and Nutrition Examination Survey. Available online: http://www.cdc.gov/nchs/nhanes/about_nhanes.htm (accessed on 8 October 2021).

4. Maggio, D.; Cherubini, A.; Lauretani, F.; Russo, R.C.; Bartali, B.; Pierandrei, M.; Ruggiero, C.; Macchiarulo, M.C.; Giorgino, R.; Minisola, S.; et al. 25(OH)D Serum levels decline with age earlier in women than in men and less efficiently prevent compensatory hyperparathyroidism in older adults. J. Gerontol. A Biol. Sci. Med. Sci. 2005, 60, 1414-1419. [CrossRef]

5. Carnevale, V.; Modoni, S.; Pileri, M.; Di Giorgio, A.; Chiodini, I.; Minisola, S.; Vieth, R.; Scillitani, A. Longitudinal evaluation of vitamin D status in healthy subjects from southern Italy: Seasonal and gender differences. Osteoporos. Int. 2001, 12, 1026-1030. [CrossRef]

6. D'Avolio, A.; Avataneo, V.; Manca, A.; Cusato, J.; De Nicolo, A.; Lucchini, R.; Keller, F.; Cantu, M. 25-Hydroxyvitamin D Concentrations Are Lower in Patients with Positive PCR for SARS-CoV-2. Nutrients 2020, 12, 1359. [CrossRef]

7. Huff, H.; Merchant, A.T.; Lonn, E.; Pullenayegum, E.; Smaill, F.; Smieja, M. Vitamin D and progression of carotid intima-media thickness in HIV-positive Canadians. HIV Med. 2017, 19, 143-151. [CrossRef]

8. Tin, A.; Zhang, L.; Estrella, M.M.; Hoofnagle, A.; Rebholz, C.M.; Brown, T.T.; Palella, F.J., Jr.; Witt, M.D.; Jacobson, L.P.; Kingsley, L.A.; et al. Vitamin D Status and Kidney Function Decline in HIV-Infected Men: A Longitudinal Study in the Multicenter AIDS Cohort Study. AIDS Res. Hum. Retrovir. 2017, 33, 1140-1148. [CrossRef]

9. Noe, S.; Oldenbuettel, C.; Heldwein, S.; Wiese, C.; von Krosigk, A.; Pascucci, R.; Ruecker, K.; Jaeger, H.; Wolf, E. Secondary Hyperparathyroidism in HIV-Infected Patients in Central Europe. Horm. Metab. Res. 2018, 50, 317-324. [CrossRef]

10. Dadabhai, A.S.; Saberi, B.; Lobner, K.; Shinohara, R.T.; Mullin, G.E. Influence of vitamin D on liver fibrosis in chronic hepatitis C: A systematic review and meta-analysis of the pooled clinical trials data. World J. Hepatol. 2017, 9, 278-287. [CrossRef]

11. Jao, J.; Freimanis, L.; Mussi-Pinhata, M.M.; Cohen, R.A.; Monteiro, J.P.; Cruz, M.L.; Branch, A.; Sperling, R.S.; Siberry, G.K. Severe Vitamin D Deficiency in Human Immunodeficiency Virus-Infected Pregnant Women is Associated with Preterm Birth. Am. J. Perinatol. 2016, 34, 486-492. [CrossRef]

12. Jimenez-Sousa, M.A.; Martinez, I.; Medrano, L.M.; Fernandez-Rodriguez, A.; Resino, S. Vitamin D in Human Immunodeficiency Virus Infection: Influence on Immunity and Disease. Front. Immunol. 2018, 9, 458. [CrossRef]

13. Lindh, J.D.; Bjorkhem-Bergman, L.; Eliasson, E. Vitamin D and drug-metabolising enzymes. Photochem. Photobiol. Sci. 2012, 11, 1797-1801. [CrossRef]

14. Drocourt, L.; Ourlin, J.C.; Pascussi, J.M.; Maurel, P.; Vilarem, M.J. Expression of CYP3A4, CYP2B6, and CYP2C9 is regulated by the vitamin D receptor pathway in primary human hepatocytes. J. Biol. Chem. 2002, 277, 25125-25132. [CrossRef]

15. Lindh, J.D.; Andersson, M.L.; Eliasson, E.; Bjorkhem-Bergman, L. Seasonal variation in blood drug concentrations and a potential relationship to vitamin D. Drug Metab. Dispos. 2011, 39, 933-937. [CrossRef]

16. Luo, G.; Guenthner, T.; Gan, L.S.; Humphreys, W.G. CYP3A4 induction by xenobiotics: Biochemistry, experimental methods and impact on drug discovery and development. Curr. Drug Metab. 2004, 5, 483-505. [CrossRef]

17. Cozzolino, M.; Vidal, M.; Arcidiacono, M.V.; Tebas, P.; Yarasheski, K.E.; Dusso, A.S. HIV-protease inhibitors impair vitamin D bioactivation to 1,25-dihydroxyvitamin D. Aids 2003, 17, 513-520. [CrossRef]

18. Burger, D.; van der Heiden, I.; la Porte, C.; van der Ende, M.; Groeneveld, P.; Richter, C.; Koopmans, P.; Kroon, F.; Sprenger, H.; Lindemans, J.; et al. Interpatient variability in the pharmacokinetics of the HIV non-nucleoside reverse transcriptase inhibitor efavirenz: The effect of gender, race, and CYP2B6 polymorphism. Br. J. Clin. Pharmacol. 2006, 61, 148-154. [CrossRef] 
19. D'Avolio, A.; Baietto, L.; Siccardi, M.; Sciandra, M.; Simiele, M.; Oddone, V.; Bonora, S.; Di Perri, G. An HPLC-PDA method for the simultaneous quantification of the HIV integrase inhibitor raltegravir, the new nonnucleoside reverse transcriptase inhibitor etravirine, and 11 other antiretroviral agents in the plasma of HIV-infected patients. Ther. Drug Monit. 2008, 30, 662-669. [CrossRef]

20. Marzolini, C.; Telenti, A.; Decosterd, L.A.; Greub, G.; Biollaz, J.; Buclin, T. Efavirenz plasma levels can predict treatment failure and central nervous system side effects in HIV-1-infected patients. Aids 2001, 15, 71-75. [CrossRef]

21. FDA. Health Based Reference Values LIAISON ${ }^{\circledR}$ Vitamin D Total Assay. Available online: https://www.accessdata.fda.gov/ cdrh_docs/reviews/K071480.pdf (accessed on 8 October 2021).

22. Cusato, J.; Genova, C.; Tomasello, C.; Carrega, P.; Ottonello, S.; Pietra, G.; Mingari, M.C.; Cossu, I.; Rijavec, E.; Leggieri, A.; et al. Influence of Vitamin D in Advanced Non-Small Cell Lung Cancer Patients Treated with Nivolumab. Cancers 2019, 11, 125. [CrossRef]

23. Cusato, J.; De Nicolo, A.; Boglione, L.; Favata, F.; Ariaudo, A.; Pinna, S.M.; Carcieri, C.; Guido, F.; Cariti, G.; Di Perri, G.; et al. Vitamin D pathway gene polymorphisms affecting daclatasvir plasma concentration at 2 weeks and 1 month of therapy. Pharmacogenomics 2018, 19, 701-707. [CrossRef]

24. Cusato, J.; De Nicolo, A.; Boglione, L.; Favata, F.; Ariaudo, A.; Mornese Pinna, S.; Carcieri, C.; Guido, F.; Avataneo, V.; Cariti, G.; et al. Vitamin D pathway genetic variants are able to influence sofosbuvir and its main metabolite pharmacokinetics in $\mathrm{HCV}$ mono-infected patients. Infect. Genet. Evol. 2018, 60, 42-47. [CrossRef]

25. Allegra, S.; Cusato, J.; De Francia, S.; Longo, F.; Pirro, E.; Massano, D.; Piga, A.; D'Avolio, A. Effect of pharmacogenetic markers of vitamin D pathway on deferasirox pharmacokinetics in children. Pharmacogenet. Genom. 2017, 28, 17-22. [CrossRef]

26. Cusato, J.; Boglione, L.; De Nicolo, A.; Favata, F.; Ariaudo, A.; Mornese Pinna, S.; Guido, F.; Avataneo, V.; Cantu, M.; Carcieri, C.; et al. Vitamin D pathway gene polymorphisms and hepatocellular carcinoma in chronic hepatitis C-affected patients treated with new drugs. Cancer Chemother. Pharmacol. 2018, 81, 615-620. [CrossRef]

27. Cusato, J.; Boglione, L.; De Nicolo, A.; Imbornone, R.; Cardellino, C.S.; Ghisetti, V.; Carcieri, C.; Cariti, G.; Di Perri, G.; D'Avolio, A. Association of vitamin D pathway SNPs and clinical response to interferon in a cohort of HBeAg-negative patients. Pharmacogenomics 2017, 18, 651-661. [CrossRef]

28. Cusato, J.; Boglione, L.; De Nicolo, A.; Cardellino, C.S.; Carcieri, C.; Cariti, G.; Di Perri, G.; D'Avolio, A. Vitamin D pathway gene polymorphisms as predictors of hepatitis C virus-related mixed cryoglobulinemia. Pharmacogenet. Genom. 2016, 26, 307-310. [CrossRef]

29. Cusato, J.; Allegra, S.; Boglione, L.; De Nicolo, A.; Baietto, L.; Cariti, G.; Di Perri, G.; D’Avolio, A. Vitamin D pathway gene variants and HCV-2/3 therapy outcomes. Antivir. Ther. 2014, 20, 335-341. [CrossRef]

30. Cusato, J.; Mula, J.; Palermiti, A.; Manca, A.; Antonucci, M.; Avataneo, V.; De Vivo, E.D.; Ianniello, A.; Calcagno, A.; Di Perri, G.; et al. Seasonal variation of antiretroviral drug exposure during the year: The experience of 10 years of therapeutic drug monitoring. Biomedicines 2021, 9, 1202. [CrossRef]

31. Cervero, M.; Agud, J.L.; Garcia-Lacalle, C.; Alcazar, V.; Torres, R.; Jusdado, J.J.; Moreno Guillen, S. Prevalence of vitamin D deficiency and its related risk factor in a Spanish cohort of adult HIV-infected patients: Effects of antiretroviral therapy. AIDS Res. Hum. Retrovir. 2012, 28, 963-971. [CrossRef]

32. Grigsby, I.F.; Pham, L.; Mansky, L.M.; Gopalakrishnan, R.; Mansky, K.C. Tenofovir-associated bone density loss. Ther. Clin. Risk Manag. 2010, 6, 41-47.

33. Havens, P.L.; Kiser, J.J.; Stephensen, C.B.; Hazra, R.; Flynn, P.M.; Wilson, C.M.; Rutledge, B.; Bethel, J.; Pan, C.G.; Woodhouse, L.R.; et al. Association of higher plasma vitamin $\mathrm{D}$ binding protein and lower free calcitriol levels with tenofovir disoproxil fumarate use and plasma and intracellular tenofovir pharmacokinetics: Cause of a functional vitamin D deficiency? Antimicrob. Agents Chemother. 2013, 57, 5619-5628. [CrossRef]

34. Kimlin, M.G. Geographic location and vitamin D synthesis. Mol. Asp. Med. 2008, 29, 453-461. [CrossRef]

35. Mormile, R. Vitamin D Intake and its Protective Role in Multiple Sclerosis: The Checkmate to Survivin? Iran J. Pharm. Res. 2016, 15, 383-384.

36. Meeker, S.; Seamons, A.; Maggio-Price, L.; Paik, J. Protective links between vitamin D, inflammatory bowel disease and colon cancer. World J. Gastroenterol. 2016, 22, 933-948. [CrossRef]

37. Liu, X.; Baylin, A.; Levy, P.D. Vitamin D deficiency and insufficiency among US adults: Prevalence, predictors and clinical implications. Br. J. Nutr. 2018, 119, 928-936. [CrossRef]

38. Klassen, K.M.; Fairley, C.K.; Kimlin, M.G.; Hocking, J.; Kelsall, L.; Ebeling, P.R. Vitamin D deficiency is common in HIV-infected southern Australian adults. Antivir. Ther. 2015, 21, 117-125. [CrossRef]

39. Ma, Q.; Vaida, F.; Wong, J.; Sanders, C.A.; Kao, Y.T.; Croteau, D.; Clifford, D.B.; Collier, A.C.; Gelman, B.B.; Marra, C.M.; et al. Long-term efavirenz use is associated with worse neurocognitive functioning in HIV-infected patients. J. Neurovirol. 2015, 22, 170-178. [CrossRef]

40. Ciccarelli, N.; Fabbiani, M.; Di Giambenedetto, S.; Fanti, I.; Baldonero, E.; Bracciale, L.; Tamburrini, E.; Cauda, R.; De Luca, A.; Silveri, M.C. Efavirenz associated with cognitive disorders in otherwise asymptomatic HIV-infected patients. Neurology 2011, 76, 1403-1409. [CrossRef]

41. Vergori, A.; Pinnetti, C.; Lorenzini, P.; Brita, A.; Libertone, R.; Mastrorosa, I.; Cicalini, S.; Antinori, A.; Ammassari, A. Vitamin D deficiency is associated with neurocognitive impairment in HIV-infected subjects. Infection 2019, 47, 929-935. [CrossRef] 